\title{
Spinal intradural arachnoid cyst with spinal dysraphism
}

Kadir Kotil, Mustafa Ali Akçetin, Necmettin Güzel, Turgay Bilge

Department of Neurosurgery, Haseki Training and Research Hospital, İstanbul, Turkey

\section{Abstract}

Spinal arachnoid cysts are relatively uncommon, they may be either intra- or extradural, among them the intradural spinal arachnoid cysts are less common. The authors report a patient with this rare lesion, in whom an anterior spinal intradural arachnoid cyst was associated with thoracic split cord malformation type I (diastematomyelia) and tethering of cord. The cyst was located anterior to the thoracic spinal cord. Our patient was an 8-year-old child who presented with progressive paraparesia. The presence of an intradural anterior arachnoid cyst was detected on magnetic resonance imaging. Surgical treatment was performed on all three lesions during the same sitting. Complete surgical excision of the cyst was the best choice of treatment with simultaneous treatment of the associated anomalies. The most important advantage of handling all three distinct lesions in one sitting, is that he was operated during a single exposure anaesthesia, which remains an important consideration in a child. The surgical treatment carried out and review of pertinent literature is being presented here. ( $J$ Pediatr Neurol 2004; 2(4): 235-239).

Key words: arachnoid cyst, spinal cord, diastematomyelia, tethered cord.

Correspondence: Kadir Kotil, M.D.,

Haseki Training and Research Hospital,

Department of Neurosurgery

Aksaray/İstanbul, Turkey.

Tel: +90 21253060 38, fax: +90 2125896229 .

E-mail: kadirkotil@superonline.com

Received: March 22, 2004

Revised: June 01, 2004.

Accepted: June 03, 2004.

\section{Introduction}

Spinal arachnoid cysts are a relatively uncommon lesion that may be either intra-or extradural. Intradural arachnoid cysts are even less common (1-5). The etiology of these lesions is unclear. Familial occurrence has been noted (6). Although it is most common to occur in association with neural tube defects, such as myelomeningocele and diastematomyelia, in some cases the cysts appear without spinal anomalies (1,3,7,9-15). An association of arachnoid cyst, diastematomyelia and tethered cord is not reported in the literature. There is a report of an anterior upper thoracic spinal arachnoid cyst with diastematomyelia (5). We believed that, it has become a gold standard in the treatment of these lesions is to try and achieve total single stage excision on the first attempt, if possible.

In this report we highlight the clinical, neuroradiological aspects, and surgical techniques as well as the results following surgical excision of an intradural arachnoid cysts located anterior to the thoracic spinal cord.

\section{Case Report}

An 8-year-old boy was admitted to our clinic, who presented with a 30-days history of progressive weakness in both lower limbs and urinary incontinence. He had no history of trauma. The child experienced progressive sensory and motor deficits below T4. Pain and temperature sensations were also decreased below T4. Deep tendon reflexes were increased in both lower extremities. Bilateral clonus was present. Bladder dysfunction (incontinence) was noted, but urodynamic study was not performed. Plain X-ray films of the cervical spine were normal. Direct lateral thoracic X-ray film revealed an abnormal bony septum located at the T11 and T12 levels. Computerized tomography (CT) myelography was not preferred, as it was an invasive method. Magnetic resonance imaging (MRI) revealed an intradural extramedullary cystic lesion located anterior to the thoracic 

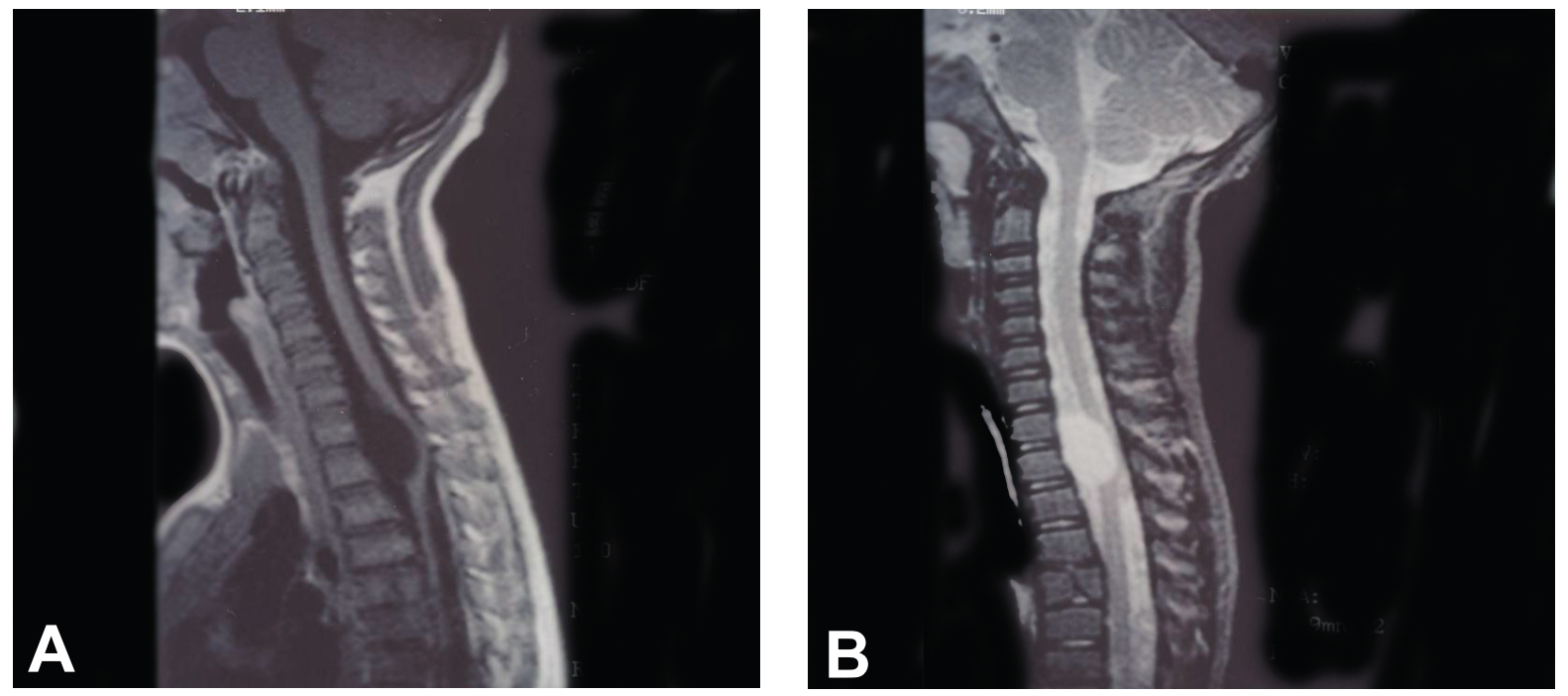

Figures 1a and 1b. a. Sagittal T1-weighted MRI revealing an intradural arachnoid cyst located completely anterior to the upper thoracic spinal cord. b. Sagittal T2-weighted MRI shows hyperintense appearance of arachnoid cyst.

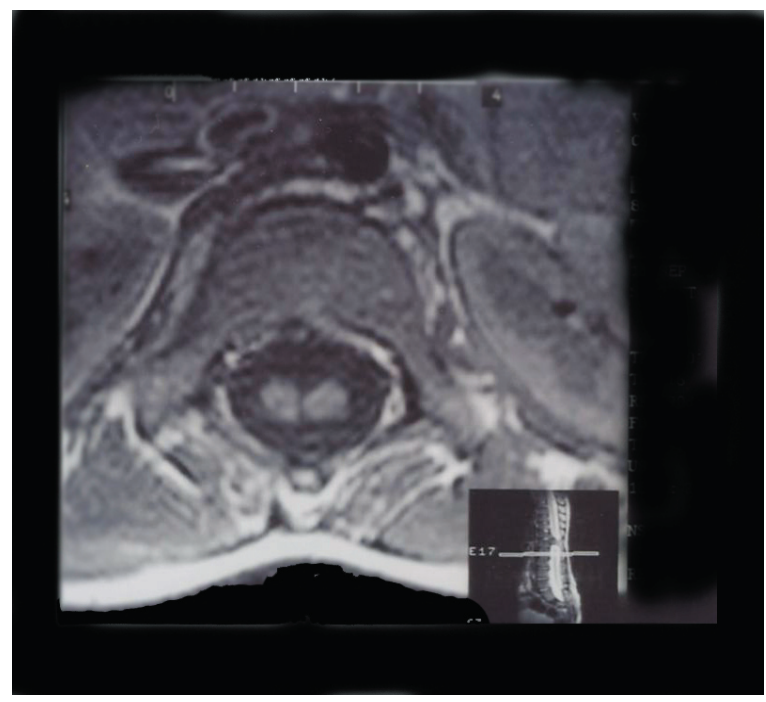

Figure 2. Axial T1-weighted MRI demonstrating a split cord malformation type 1 compressing to the lower thoracic spinal cord (epiconus).

spinal cord at the T1-T2 levels (Figures 1a and 1b). The second abnormality was a split cord (type 1) malformation at the T11-L1 levels (Figure 2 ), and the third was a tethered cord at the L5-S1 level (Figure 3).

At surgery, dorsal midline incisions were made at three different levels, the first between $\mathrm{T} 1$ and $\mathrm{T} 2$, the second between $\mathrm{T} 11$ and $\mathrm{T} 12$, and the last incision at L5-S1 levels in the same position and sitting. In the first surgical stage, the first pathology (arachnoid cyst) was operated, laminectomy was performed, the dura was opened, the spinal cord was observed to be rotated to the left and displaced posteriorly. The arachnoid cyst caused a bulge and compression of spinal cord on the right side. There was no connection between the cyst and subarachnoid space (non communicating cyst). Incision on the cyst allowed cerebrospinal fluid (CSF) to flow out,

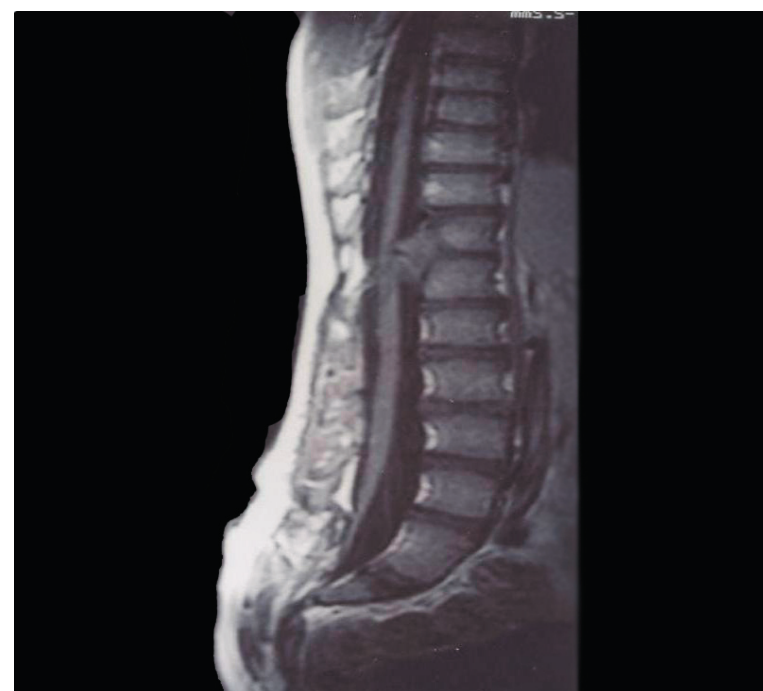

Figure 3. Sagittal MRI shows a tethered cord at the L5S1 levels.

following which the spinal cord became lax. Using microsurgical techniques, we removed as much of the arachnoid trabeculations and septations of by cyst, and this we fenestrated the cyst to create a free communication with subarachnoid space. There was not coexistence of anomalous vessels on the dorsal aspect of the spinal cord. In the second stage, the filum was cut, and later the spur causing split cord malformation was resected. Thus spinal cord was released to ascend up. Total laminectomy was performed above and below the bony septum and intraspinal bone was removed laterally to expose the dural cleft. Anterior and posterior dura was closed in a watertight fashion.

Histopathological examination of the specimen of cyst revealed an arachnoid cyst. Postoperative MRI documented a relief of spinal cord compression and release of tethering (Figures $4 \mathrm{a}$ and 4b). 

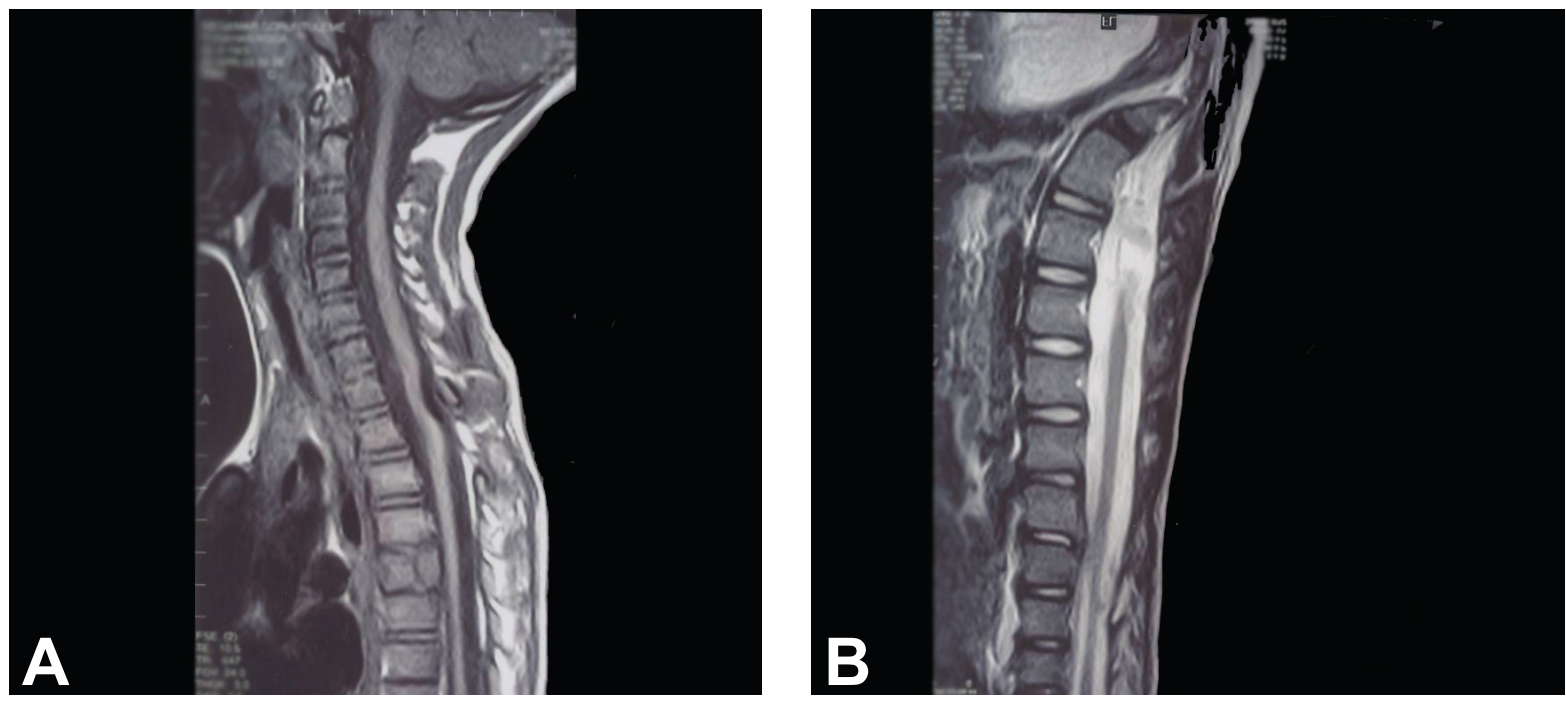

Figures 4a and 4b. Sagittal T1-weighted, MRI revealing an intradural cyst after complete resection, Sagittal T2weighted MRI obtained in the thoracolumbar region revealing resected split cord and released filum terminale.

Table 1. Clasification of spinal arachno-meningeal cyst

\begin{tabular}{ll}
\hline \hline Types & Descriptions \\
\hline 1 & $\begin{array}{l}\text { Extradural meningeal cysts w/o spinal nerve } \\
\text { root fibers }\end{array}$ \\
$1 \mathrm{~A}$ & $\begin{array}{l}\text { Extradural meningeal cyst (extradural } \\
\text { arachnoid cyst) }\end{array}$ \\
$1 \mathrm{~B}$ & $\begin{array}{l}\text { Sacral meningosel (occult sacral meningosel) } \\
\text { Extradural meningeal cyst w/o spinal nerve } \\
\text { root fibers } \\
\text { Spinal intradural meningeal cyst (intradural } \\
\text { arachnoid cyst) }\end{array}$ \\
\hline \hline
\end{tabular}

The symptoms improved progressively after the surgery. By the time of discharge all residual neurological deficits improved. At follow up of one month, neurological examination revealed no motor or sensory dysfunction.

\section{Discussion}

In this report, we describe a patient with intradural arachnoid cyst, who had a neural tube defect. Spinal arachnoid cysts located anterior to the spinal cord have been reported on seven occasions, with four of the seven in the pediatric age group (4), and all four in the cervical region. In our case, the cyst was located in the anterior thoracic region at the T1 level. The series of spinal arachnoid cysts reported by Rabb et al. (5) included a case of a split cord malformation along with an extradural cyst in the lumbosacral region.

Spinal arachnoid cysts have been termed as "arachnoid divertucula", "leptomeningeal cyst", "localized adhesive arachnoiditis", or "serious spinal meningitis" according to the different pathogenic conceptions (7-8). However, Nabors et al. (3) have called these entities as "cyst" for the sake of simplicity, in order to avoid further confusion in the nomenculature (Table 1). Most patients harboring arachnoid cysts are asymptomatic. Non-communicating intradural extramedullary arachnoid cysts are rarer than communicating intradural extramedullary cysts. Non-communicating intradural extramedullary arachnoid cysts very rarely cause spinal cord compression (16). Our case had non-comunicating intradural extramedullary cyst.

Intradural arachnoid cysts are commonly found in the spinal cord at the thoracic spine region, however, they may develop in the cervical and lumbar segments as well (1,4,5,15-19). Intraspinal arachnoid cysts originate from the arachnoid of the spinal cord, which extends to the sheaths of the spinal nerve roots. Ventral cysts are more likely to cause weakness and myelopathic features $(1,2-$ 6,9-15). These cysts are relatively uncommon but they must be differentiated from other congenital intraspinal cystic lesions, such us neuroepithelial, neuroenteric cysts, teratoid cysts, and acquired cystic cavities (20). The definitive diagnosis, however, is reached through biopsy only.

Some cysts result from post-inflammatory adhesions within the subarachnoid space (9), the cause of these remains obscure, some cysts are ascribed anecdotally to previous trauma or arachnoiditis (21), whereas, the majority are idiopathic and assumed to be congenital. Aarabi et al. (6) have reported two proven cases of intradural arachnoid cysts over two generations in a family with five paraparethic members. The mode of inheritance in this particular family was probably Mendelian dominant. It has also been postulated that intradural cysts result from widening of the septum posticum (7). In the thoracic and cervical spine this septum 
divides from the dorsal subarachnoid space in the midline. However, this hypothesis does not explain the origin of it's location at anterior aspect of the spinal cord as found in our and other cases. It also fails to account for cysts in the lumbar spine region. In addition, Agnoli et al. (9) have postulated that intradural arachnoid cyst results from a pathological distribution of the arachnoid trabeculae and that this pathological arrangement leads to a diverticulum. The degenerated trabecular cells increase the pressure within the cyst, which shows an oncotic effect resulting from transudation of fluid in the cyst (9).

Our case had arachnoid trabeculations and septations. Additionally, the cyst was not communicating with the subarahnoid space. These findings support the hypothesis of Agnoli et al. (9). Other possible causes include inflamatory meningitis due to viruses, spirochetes, or bacteria and chemical meningitis secondary to subarachnoid hemorrhage, contrast media, spinal anesthetic agents, and spinal operations (7-11). These lead to scar formation, which separate the subarachnoid space into diverticula or cysts. Associated tethering lesions, not directly related to the split cord malformation are also common (9).

The diagnosis of intradural arachnoid cysts is difficult $(2,8)$. Plain X-ray films of these spinal lesions are usually not helpful in the diagnosis. When the cysts occur in the thoracic spine region, the radiographic studies can sometimes reveal a kyphotic deformity with signs of long-standing pressure in the form of scalloping of the posterior surface of the vertebral bodies, thinning of the pedicles, and widening of the canal. Myelography and CT-myelography are still of diagnostic values, since they might demonstrate the communication between the subarachnoid space and the cyst, which is important for surgical planning (20,22-23). According to Chan et al. (7) the most important preoperative diagnostic procedure is myelography performed in both supine and prone positions.

Unfortunately, we do not have any experience about CT myelography. The presence of spinal intradural arachnoid cysts can be demonstrated with modern imaging studies such as MRI (12). However, T2-weighted MRI demonstrates heterogeneous signal intensity, depending on the flow effect in the cyst fluid, which may be the only evidence to indicate presence of an abnormal fluid collection. The MRI scans demonstrate the intradural arachnoid cysts with slightly lower CSF signal intensity on the gradient echo images and slightly higher signal intensity on T1-weighted images. In these cases, it has been reported that cine MR imaging can demonstrate abnormal fluid flow and spinal cord compression caused by a spinal intradural arachnoid cyst. Endoscopy can also be useful tool to diagnose or rule out a cyst $(12,25)$

Surgical treatment is generally indicated in patients with symptomatic spinal intradural arachnoid cyst, split cord malformation, and tethered cord. Most of the symptoms and signs are produced by arachnoid cyst. Firstly, we performed cyst fenestration, and then operated the tethered cord and lastly spur resection. We suggest that a combined intervention can be performed in one surgical sitting. If a patient had normal phsyical examination a surgical intervention can include cyst excision, fenestration and placement of a shunt. There is a general agreement that the successful treatment of a spinal arachnoid cyst requires a total excision, wherever possible. However, in cases, in which the cyst cannot be resected completely because of dense fibrous adhesion to the spinal cord or nerve roots and/or place of anterior to the spinal cord, partial resection and fenestration should be performed as widely as possible. Intradural arachnoid cysts have been reported to recur after incomplete excision (13). These lesions have been fenestrated percutaneously by using real-time MRI guidance and a local anesthetic agent (14). MRIguided fenestration can be considered a minimally invasive option for intradural cystic lesions. In the literature, there is only one death attributed to misdiagnosis and infection (4).

In conclusion, modern imaging techniques make the diagnosis of an arachnoid cyst easier. An intradural arachnoid cyst located anterior to the upper thoracic spinal cord, associated split cord type 1 malformation and tethering of cord is a rare case, that may cause progressive myelopathy; however, the postoperative prognosis is good if the operation is performed prior to neurological deficit. We recommend one stage surgical procedure for the associated abnormalities. The most important advantage in a child remains of handling three distinct lesions in a single surgical sitting with a single exposure of anaesthesia. We think that the operative treatment in a single session has the advantage of preventing metabolic stress that occurs from anesthetic agents.

\section{References}

1. Lee HJ, Cho DY. Symptomatic spinal intradural arachnoid cysts in the pediatric age group: description of three new cases and review of the literature. Pediatr Neurosurg 2001; 35: 181-187.

2. Lesoin F, Leys D, Rousseaux M, Cama A, Jomin M, Petit H. Spinal intradural arachnoidcysts. Acta Neurochir 1985; 76: 125-128.

3. Nabors MW, Pait TG, Byrd EB. Updated assessment and current classification of spinal meningeal cysts. J Neurosurg 1988; 68: 366-377.

4. Palmer JJ. Spinal arachnoid cysts. Report of six cases. J Neurosurg 1974; 41: 728-735. 
5. Rabb CH, McComb JG, Raffel C, Kennedy JG. Spinal arachnoid cysts in the pediatric age group an association with neural tube defects. J Neurosurg 1992; 77: 369-372.

6. Aarabi B, Pasternak G, Hurko O, Long DM. Familial intradural arachnoid cysts. Report of two cases. J Neurosurg 1979; 50: 826-829.

7. Chan RC, Thompson GB, Bratty PJ. Symptomatic anterior spinal arachnoid diverticulum. Neurosurgery 1985; 16: 663-665.

8. Fortuna A, La Torre E, Ciappetta P. Arachnoid diverticula: a unitary approach to spinal cysts communicating with the subarachnoid space. Acta Neurochir 1977; 39: 259-268.

9. Agnoli AL, Schonmayr R, Laun A. Intraspinal arachnoid cysts. Acta Neurochir 1982; 61: 291-302.

10. Kazan S, Özdemir O, Akyüz M, Tuncer R. Spinal intradural arachnoid cysts located anterior to the cervical spinal cord. Report of two cases and review of the literature. J Neurosurg 1999; 91: 211-215.

11. Kumar R, Taha J, Greiner AL. Herniation of the spinal cord. Case report. J Neurosurg 1995; 82: 131136.

12. Shimizu H, Tominaga T, Takahashi A, Yoshimoto T. Cine magnetic resonance imaging of spinal intradural arachnoid cysts. Neurosurgery 1997; 41: 95-100.

13. Jensen F, Knudsen V, Troelsen S. Recurrent intraspinal arachnoid cyst treated with a shunt procedure. Acta Neurochir 1977; 39: 127-129.

14. Takahashi S, Morikawa S, Egawa M, Saruhashi Y, Matsusue Y. Magnetic resonance imaging-guided percutaneous fenestration of a cervical intradural cyst. Case report. J Neurosurg 2003; 99: 313-315.

15. Wang MY, Levi AD, Green BA. Intradural spinal arachnoid cysts in adults. Surg Neurol 2003; 60: 4955.
16. Kumar K, Malik S, Schulte PA. Symptomatic spinal arachnoid cysts: report of two cases with review of the literature. Spine 2003; 28: 25-29.

17. Safriel YI, Sanchez G, Jhaveri HS. Giant anterior cervicothoracic arachnoid cyst. Spine 2002; 27: 366 368 .

18. Abou-Fakhr FS, Kanaan SV, Youness FM, Hourani MH, Haddad MC. Thoracic spinal intradural arachnoid cyst: report of two cases and review of literature. Eur Radiol 2002; 12: 877-882.

19. Shibata $T$, Nakamura H, Yamano Y. Intradural arachnoid cyst associated with thoracic spinal compression fracture: 7-year follow up after surgery Spinal Cord 2001; 39: 599-601.

20. Willems PW, van den Bergh WM, Vandertop WP. An arachnoid cyst presenting as an intramedullary tumour. J Neurol Neurosurg Psychiatry 2000; 68: 508-510.

21. Honda E, Fujisawa H, Koyama T, Oshima Y, Sugita Y, Abe T. Symptomatic spinal arachnoid cyst triggered by seat belt injury--case report. Neurol Med Chir 1998; 38: 168-172.

22. Krings T, Lukas R, Reul J, et al. Diagnostic and therapeutic management of spinal arachnoid cysts. Acta Neurochir 2001; 143: 227-234.

23. Gelabert-Gonzalez M, Cutrin-Prieto JM, GarciaAllut A. Spinal arachnoid cyst without neural tube defect. Child's Nerv Syst 2001; 17: 179-181.

24. Silbergleit R, Brunberg JA, Patel SC, Mehta BA, Aravapalli SR. Imaging of spinal intradural arachnoid cysts: MRI, myelography and CT. Neuroradiology 1998; 40: 664-668.

25. Fujimura M, Tominaga T, Koshu K, Shimizu H, Yoshimoto T. Cine-mode magnetic resonance imaging of a thoracic intradural arachnoid cyst: case report. Surg Neurol 1996; 45: 533-536. 